\title{
Short-term Heat Exposure Promotes Hippocampal Neurogenesis via Activation of Angiotensin II Type 1 Receptor in Adult Rats
}

\author{
Yuka Koyama, Takao Mukuda, * Sawako Hamasaki, Hironobu Nakane and Toshiyuki Kaidoh \\ Department of Anatomy, Faculty of Medicine, Tottori University, 86 Nishi-cho, Yonago 683-8503, Japan
}

\begin{abstract}
Angiotensin II (Ang II) synthesized in response to body fluid loss caused by actions such as sweating and breathing is today considered as one of the essential factors for promoting hippocampal neurogenesis. Because heat stimuli, along with exercise, increase systemic levels of Ang II, the effects of short-term heat exposure on hippocampal neurogenesis were examined in adult male rats. When rats were exposed daily to a 1-h heat treatment $\left(36.0 \pm 0.1^{\circ} \mathrm{C}\right)$ during a 7 -d experimental period, the number of doublecortin-immunoreactive newborn cells in the hippocampal dentate gyrus was increased approximately 1.4-fold compared with that in controls that were exposed to a normothermic environment $\left(25.0 \pm 0.8^{\circ} \mathrm{C}\right)$. No significant change was observed in the number of Ki-67-immunoreactive stem cells. Western blot and immunohistochemical analyses revealed an enhancement of vascular endothelial growth factor (VEGF) expression in hippocampal astrocytes following short-term heat exposure. These beneficial effects of short-term heat exposure were prevented when an antagonist for Ang II type 1 receptor (AT1R), candesartan, was given orally. These results indicate that short-term heat exposure enhances adult neurogenesis via activation of AT1R in the hippocampal dentate gyrus, in which VEGF may participate by promoting cell proliferation and/or newborn neuron survival. @ 2018 IBRO. Published by Elsevier Ltd. All rights reserved.
\end{abstract}

Key words: neurogenesis, hippocampus, short-term heat exposure, angiotensin II type 1 receptor, candesartan, vascular endothelial growth factor.

\section{INTRODUCTION}

Hippocampal neurogenesis continues throughout life in mammals, exclusively in the subgranular zone of the dentate gyrus. It underlies several behaviors involving hippocampal function, including memory, spatial navigation and emotional responses (van Praag et al., 1999; Cao et al., 2004; Vaynman et al., 2004; Udo et al., 2008; Speisman et al., 2013). Hippocampal neurogenesis is modulated by both internal and external stimuli. Along with exposure to enriched environments, physical exercise such as running is well known to be a robust stimulus to enhance hippocampal neurogenesis in rodents (van Praag et al., 1999; Fabel et al., 2003; Mukuda and Sugiyama, 2007; Akhavan et al., 2008; Speisman et al., 2013; Mukuda et al., 2014). The enhanced neurogenesis resulting from physical exercise is mediated by trophic factors, including vascular

\footnotetext{
*Corresponding author. Fax: +81-859-38-6020.

E-mail address: mtakao@tottori-u.ac.jp (T. Mukuda).

Abbreviations: AGT, angiotensinogen; Ang II, angiotensin II; AT1R, Ang II type 1 receptor; AT2R, Ang II type 2 receptor; BDNF, brainderived neurotrophic factor; CONT, control; DCX, doublecortin; GFAP, glial fibrillary acidic protein; HEAT, heat exposure; PBS, phosphatebuffered saline; RAS, renin-angiotensin system; VEGF, vascular endothelial growth factor.
}

endothelial growth factor (VEGF) and brain-derived neurotrophic factor (BDNF), which promote cell proliferation, neuronal differentiation and newborn cell survival (Fabel et al., 2003; Vaynman et al., 2004; Udo et al., 2008; Umschweif et al., 2014). Although physical exercise is beneficial for hippocampal neurogenesis, it may be difficult to undertake because of injury, disease or aging. It is therefore desirable to develop alternative treatment strategies that offer similar benefits, together with improved ease of use and safety.

A bioactive octapeptide of the renin-angiotensin system (RAS), angiotensin II (Ang II), is produced from angiotensinogen (AGT) through a complex cascade, in which the peptide levels are precisely controlled by the rate-limiting enzyme, renin. The circulating RAS is mainly known for its pivotal role in maintaining body fluid and electrolyte balance, together with cardiovascular homeostasis, and Ang II is acutely synthesized in response to body fluid loss caused by actions such as sweating, accelerated salivation and breathing. In addition to the peripheral RAS, a local RAS has been widely accepted to exist independently in the brain, which regulates various brain functions (Huber et al., 2017). These peripheral and central responses are exerted by Ang II, which acts on its receptor subtypes. Vasoconstriction and thirst perception elicit water intake and are well-characterized responses evoked by 
activating Ang II type 1 receptor (AT1R). However, overactivity of AT1R is known to evoke many peripheral and brain diseases, including heart failure and stroke (Saavedra, 2017).

Recently, we found that running exercise increases systemic Ang II levels up to double those of resting levels and promotes water intake in adult rats (Mukuda et al., 2014). We also showed that the enhanced hippocampal neurogenesis induced by running exercise is mediated by AT1R in adult rats, because a specific antagonist for AT1R, losartan, abolished the beneficial effect (Mukuda and Sugiyama, 2007). Further, increasing systemic Ang II levels by intravascular injection of the peptide mimics the enhancements observed following exercise (Mukuda et al., 2014). AT1R activation in the brain is suggested to be essential for the improvement of hippocampal function resulting from physical exercise in adult rats (Akhavan et al., 2008). Blockade of AT1R using antagonists increases opportunities for Ang II to activate another receptor subtype, Ang II type 2 receptor (AT2R); nevertheless, no positive or negative effects were found in these studies. However, AT2R may participate in hippocampal neurogenesis mainly in developmental stages and/or pathological states. Activation of AT2R induces proliferation of neuronal stem cells derived from the fetal hippocampus (Chao et al., 2013). In addition, following traumatic brain injury in mice, enhanced hippocampal neurogenesis is mediated by AT2R (Umschweif et al., 2014a). Taken together, an acute and transient increase of systemic Ang II and consequent activation of AT1R is likely to be important for the improvement of hippocampal function, probably through enhanced neurogenesis, in physiologically normal adult rodents.

Similar to physical exercise, exposure to a heated environment induces body fluid loss and physiologically increases systemic Ang II, as shown in a study in mice where heat exposure $\left(37.5^{\circ} \mathrm{C}, 4 \mathrm{~h}\right)$ led to an approximately twofold increase in systemic Ang II levels compared with those of control mice (Wang et al., 2015). However, it should be noted that this was a relatively long-term exposure to heat. The effects of shortterm heat stimulation on hippocampal neurogenesis are not clear, although the effects of hyperthermic acclimation have been examined in some studies. For instance, hyperthermic acclimation established by long-term maintenance in a heated environment $\left(34^{\circ} \mathrm{C}, 28\right.$ days) promotes hippocampal neurogenesis in mice given traumatic injury to the cerebral cortex (Umschweif et al., 2014b). Conversely, hyperthermic acclimation induced by maintenance at $32^{\circ} \mathrm{C}$ for $40-50$ days was ineffective at promoting hippocampal neurogenesis in physiologically normal rats (Matsuzaki et al., 2015). The aim of the present study was to examine the effects of short-term moderate heat exposure $\left(36^{\circ} \mathrm{C}, 1 \mathrm{~h} /\right.$ day, 7 days), which does not lead to chronic distress, on neurogenesis and expression of the neurotrophic factors VEGF and BDNF in the hippocampus of adult rats. Our findings provide support for the prospect of thermal therapy to maintain and improve the structural integrity and function of the hippocampus.

\section{EXPERIMENTAL PROCEDURES}

\section{Animals and surgical procedures}

All animal experiments were performed in accordance with the Guidelines for the care and use of laboratory animals of Tottori University and Guidelines for Proper Conduct of Animal Experiments decreed by Science Council and Ministry of Education, Culture, Sports, Science and Technology of Japan. All experimental protocols were approved by Tottori University Institutional Animal Care and Use Committee (approved protocol numbers: $14-\mathrm{Y}-27,17-\mathrm{Y}-14)$.

A total of 27 male Wistar rats bred in our laboratory were used for the study. The animals were housed under standard conditions of $12 \mathrm{~h} / 12 \mathrm{~h}$ light/dark cycle at $24-26^{\circ} \mathrm{C}$, with free access to food and water. Twenty-week-old rats were randomly allocated to four groups: control (CONT), short-term exposure to heat (HEAT), control given an antagonist for the AT1R, candesartan (cds-CONT) and heat-exposed rats treated with candesartan (cds-HEAT). All rats were implanted with catheters into the right atrium via the right jugular vein to collect blood samples, as described in detail previously (Mukuda et al., 2014). Briefly, rats were anesthetized by intraperitoneal injection of thiamylal sodium (60 mg/kg, Nichi-lko Pharmaceutical, Toyama, Japan). After shaving the hair of the right chest (clavicle) and dorsal neck, rats were placed ventral side up and a small incision was made in the right supraclavicular skin to provide access to the right jugular vein. The jugular vein was isolated from the subcutaneous fatty tissue and a small cut was made, through which a polyurethane tube (1.02$\mathrm{mm}$ outer diameter, MRE-040, Eicom, Kyoto, Japan) primed with heparinized saline (10-unit heparin sodium in $1 \mathrm{ml} 0.9 \% \mathrm{NaCl}$ ) was inserted toward the right atrium. The catheter was secured in the blood vessel with cotton threads. The distal tip of the catheter was capped and passed through the cervical subcutaneous tissue toward the back and exteriorized through a small incision on the dorsal neck skin. The incisions were sutured with cotton threads and wiped clean. After surgery, rats were housed individually with fresh bedding for at least three days to allow them to recover. The catheter was flushed daily with heparinized saline $(<50 \mu \mathrm{L})$ to prevent it from clogging.

\section{Experimental design}

A schematic of the experimental schedule is shown in Fig. 1. Rats were individually housed in home cages throughout the experimental period. Short-term daily heat exposure of 1-h duration was chosen for the present study because long-term heat exposure $\left(37.5^{\circ} \mathrm{C}, 4 \mathrm{~h}\right.$ ) was reported to be lethal (Barney et al., 2015).

A temperature-controlled chamber was heated to a constant ambient temperature of $36.0 \pm 0.1^{\circ} \mathrm{C}$ with $45 \%$ humidity. For short-term heat exposure, home cages of rats in the HEAT group were transferred to the heated chamber. Short-term heat exposure was started at 10:00 daily for 7 consecutive days, under light. Home cages of rats in the CONT group were transferred to a 


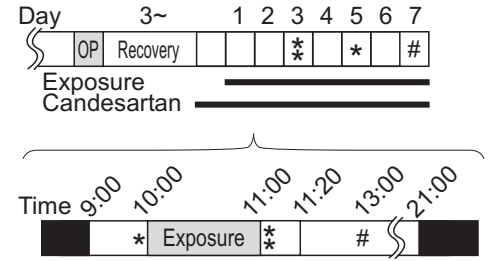

OP: Surgical operation to implant intra-atrial catheter

* : Blood sampling for circadian resting phase on day 5

* : Blood sampling for post-exposure on day 3

\# : Brain sampling on day 7

Fig. 1. Experimental timeline. Normothermic (CONT) or hyperthermic (HEAT) temperatures were set at $25.0 \pm 0.8^{\circ} \mathrm{C}$ and $36.0 \pm$ $0.1^{\circ} \mathrm{C}$, respectively.

chamber held at $25.0 \pm 0.8^{\circ} \mathrm{C}$ (i.e., normothermic) with $45 \%$ humidity. Food and water were removed during exposure. After the exposure, drinking water was put in each cage and the 20-min water intake was measured.

For blood sampling to measure systemic levels of hormones and plasma osmolality before and after the exposure, blood $(500 \mu \mathrm{L})$ was collected using the intraatrial catheter under free moving conditions. Because levels of hormones can be drastically altered in response to handling for blood collection or hypovolemia, the number of blood samplings within the experimental schedule was kept to a minimum (a total of twice per animal). To determine the basal level of each factor, blood was taken from rats immediately before the normothermic or hyperthermic exposure at around 10:00 (i.e., circadian resting phase) on day 5 of the experiment. To measure post-exposure levels, a sample was taken within 3 min after finishing the exposure, at around 11:00, on day 3. After finishing blood sampling for the postexposure levels, drinking water for measuring the 20-min water intake was supplied. The same protocols were applied to rats given the AT1R antagonist candesartan (cds-CONT and cds-HEAT groups). Candesartan cilexetil (Atacand, AstraZeneca, Cambridge, UK) was given to rats every day from $24 \mathrm{~h}$ prior to the start of the heat exposure, by dissolving the chemical in drinking water $(0.012 \mathrm{mg} / \mathrm{mL})$. Rats could freely access the water bottles. The net dose of candesartan was estimated at $1.6-1.8 \mathrm{mg} / \mathrm{kg} / \mathrm{day}$, calculated based on daily water intake and body weight (see Fig. 2). This dose has been reported to sufficiently block AT1R both in central and peripheral tissues, and attenuates responses stimulated by intracerebroventricularly injected Ang II (Gohlke et al., 2002).

\section{Sample preparation}

Two hours after heat exposure on the last day of the experimental period, rats were deeply anesthetized by injection of an excess of thiamylal sodium via the catheter, and the forebrains were immediately isolated. The isolated forebrains were further separated into left and right hemispheres by a midline incision. The left and right hemispheres were used for immunohistochemical and biochemical analyses, respectively.

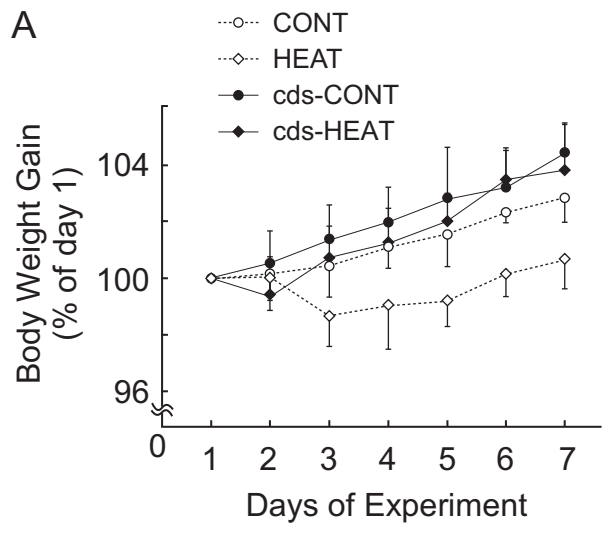

B

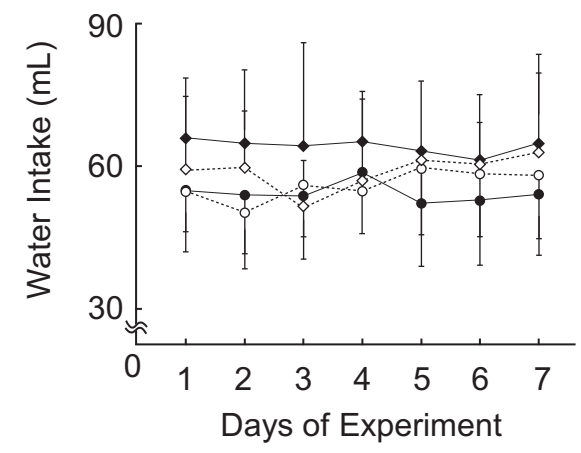

Fig. 2. Body weight and water intake in rats exposed daily to shortterm heat treatment. (A) Body weight gain (\%) relative to experimental day 1. (B) Average water intake $(\mathrm{mL} /$ day). Broken lines indicate data of normothermic (CONT $(\bigcirc, n=7))$ and heat-exposed (HEAT $(\diamond, n=7))$ groups. Solid lines show data of rats treated with candesartan (1.6-1.8 mg/kg/day): cds-CONT $(\bullet, n=6)$ and cdsHEAT $(\diamond, n=7)$. Values are expressed as mean \pm SD. Data were analyzed using a two-way repeated measures ANOVA.

\section{Immunohistochemistry}

The left hemispheres were immediately immersed in icecold fixative of $4 \%$ paraformaldehyde (PFA) in $0.1 \mathrm{M}$ phosphate buffer (PB, pH 7.4) and kept at $4{ }^{\circ} \mathrm{C}$ for $48 \mathrm{~h}$. The fixed hemispheres were cryoprotected by immersing in $30 \%$ sucrose in $0.1 \mathrm{M} \mathrm{PB}$ for $48 \mathrm{~h}$ at $4{ }^{\circ} \mathrm{C}$, then embedded in medium (OCT Compound, Sakura, Tokyo, Japan). Specimens were coronally cut to $20-\mu \mathrm{m}$ thick sections using a freezing microtome (CM1520, Leica, Wetzlar, Germany). Cryosections were mounted onto adhesive-coated glass slides (FRC-04, Matsunami, Osaka, Japan). To examine the effects of short-term heat exposure on hippocampal neurogenesis, a series of every 12th section (a total of 20 sections with $240-\mu \mathrm{m}$ intervals) through the entire dentate gyrus was selected from each animal and immunostained for $\mathrm{Ki}-67$ as a marker for proliferating cells and doublecortin (DCX) for newborn immature neurons. The nuclear protein $\mathrm{Ki}-67$ is expressed by cells throughout the cell cycle with the exception of a short period at the beginning of $\mathrm{G} 1$ (Tanapat et al., 1999). The microtubule-associated protein DCX is required for the initial steps of neuronal dispersion and is expressed exclusively in immature neurons within 2 weeks after cell birth; therefore DCX is often used as a marker to measure the level of neurogenesis (Couillard-Despres et al., 2005). A second 
series of sections, neighboring the sections used for Ki-67 and DCX double-staining, was immunostained for VEGF together with glial fibrillary acidic protein (GFAP), which is a marker of astrocytes. The level of each section almost corresponded to that assigned to the odd plate number from 49 to 87 of the rostro-caudal stereotaxic coordinates of the rat brain atlas, where the dentate gyrus was clearly distinguishable (bregma -1.92 to $-6.48 \mathrm{~mm}$ ) (Paxinos and Watson, 2009).

Sections were boiled in $10 \mathrm{mM}$ sodium citrate buffer $(\mathrm{pH} 6.0)$ for $10 \mathrm{~min}$ for antigen retrieval. After cooling to $\mathrm{RT}$, sections were rinsed in phosphate-buffered saline (PBS) and incubated with a blocking solution (PBS containing $5 \%$ normal donkey serum, $0.1 \%$ Triton-X100 and $0.05 \%$ Tween 20 ) for $1 \mathrm{~h}$ at RT. Sections were then incubated with primary antisera for $48-96 \mathrm{~h}$ at $4{ }^{\circ} \mathrm{C}$. After rinsing with PBS, sections were incubated with secondary antisera together with 4',6-diamidino-2-phenylindole (DAPI, 1:1,000, D9542, Sigma-Aldrich, St. Louis, $\mathrm{MO})$ for $2 \mathrm{~h}$ at RT. Sections were embedded and coverslipped after rinsing in PBS. Primary and secondary antisera were diluted in diluent (omitting Triton-X100 and Tween 20 from the blocking solution) as follows: rabbit polyclonal anti-Ki-67 antibody (1:500, RM-9106-S, Thermo Scientific, Fremont, CA, USA); goat polyclonal anti-DCX antibody (1:250, SC-8066, Santa Cruz Biotechnology, Dallas, TX); rabbit polyclonal anti-VEGF antibody (1:750, RB-222-P, Thermo Scientific); goat polyclonal anti-GFAP antibody (1:1000, ab53554, Abcam, Cambridge, UK); donkey anti-rabbit IgG antibody conjugated with the fluorophore Cy2 (1:500, 711-225152, Jackson ImmunoResearch Laboratories, West Grove, PA); donkey anti-goat IgG antibody conjugated with the fluorophore Cy3 (1:500, 705-165-147, Jackson ImmunoResearch Laboratories).

Immunostained preparations were examined under a fluorescence microscope (BX51, Olympus, Tokyo, Japan) equipped with a digital full color camera (DP73, Olympus). Exposure time was adjusted to avoid saturation and photo bleaching. For each experiment, the same optimized conditions were applied to the series of samples. Images were acquired and analyzed using cellSens software (Olympus). To discriminate each cell in immunopositive cell clusters, immunofluorescent images were obtained with a $20 \times$ or $40 \times$ objective lens and processed using the extended focus imaging mode of the software, which creates a single in-focus image from successive image planes.

For quantitative analyses of Ki-67 and DCX immunohistochemistry, stained cells in the subgranular zone, defined as the area between the granule cell layer and hilus in the hippocampal dentate gyrus, were counted manually using all sections. The total number of immunoreactive cells counted was used for comparison between the groups.

\section{Western blot analysis}

The right hippocampi were isolated from the forebrain hemispheres on ice, put into plastic vials, frozen quickly using dry ice-ethanol and kept at $-80^{\circ} \mathrm{C}$. Each hemisphere was homogenized in a $1.5-\mathrm{mL}$ plastic microtube using a vibrating conical pestle on ice, and total protein was extracted from the homogenate in PBS containing protease inhibitor (Protease Inhibitor Cocktail Set V, EDTA-free, Wako, Osaka, Japan). Then the sample was centrifuged at $12,000 \times g$ at $4{ }^{\circ} \mathrm{C}$ for $5 \mathrm{~min}$. The protein concentration in each sample was determined using a protein assay kit (Pierce BCA Protein Assay Kit, Thermo Scientific) and was adjusted to the same value in all samples with sample buffer $(62.5 \mathrm{mM}$ Tris- $\mathrm{HCl} \mathrm{pH} 6.8,2 \%$ SDS, 5\% 2-mercaptoethanol, 10\% glycerol). The proteins were separated by SDS-PAGE using 10-20\% polyacrylamide gels (SuperSep Ace, Wako) and electrotransferred to PVDF membranes (ClearTrans, Wako) for detection of Ang II, AT1R, VEGF and BDNF. The membranes were washed with Trisbuffered saline containing $0.1 \%$ Tween 20 (TBST, pH 7.6). After blocking with TBST containing $0.3-5 \%$ skim milk, the membranes were probed with antiangiotensinogen (AGT, 1:1000, sc-7419, Santa Cruz), anti-AT1R (1:1000, AT11-A, Alpha Diagnostic International, San Antonio, TX, USA), anti-VEGF (1:2500, RB-222-P1, Thermo Scientific) or anti-BDNF (1:1000, ab72439, Abcam) antibodies. After washing with TBST, the bound antibodies were detected with a horseradish peroxidase-conjugated donkey anti-goat (1:5000, HAF 109, R\&D Systems, Minneapolis, MN, USA) or anti-rabbit (1:5000-10,000, NA934, GE Healthcare, Little Chalfont, UK) IgG secondary antibody. After washing with TBST, the reactive bands were visualized with an enhanced chemiluminescence reagent (ImmunoStar Zeta, Wako).

\section{ELISA and plasma osmolality measurement}

Blood samples were mixed with one tenth the volume of $0.1 \mathrm{M}$ sodium citrate buffer and centrifuged at $3500 \times \mathrm{g}$ at $4{ }^{\circ} \mathrm{C}$ for $15 \mathrm{~min}$. Plasma concentrations of hormones were measured using commercial ELISA kits for Ang II (Phoenix Pharmaceuticals, Burlingame, CA, USA) or corticosterone (Assaypro, St. Charles, MO, USA), according to the manufacturer's instructions. All assays were performed in duplicate. Plasma osmolality was measured using an osmometer (Vapro Osmometer 5520, Wescor, Logan, UT, USA).

\section{Statistics}

All data were expressed as the mean \pm SD. Statistical significance was determined by a two-way analysis of variance (ANOVA) for factors: exposure (normothermic and hyperthermic) and drug treatment (control and candesartan). The Tukey-Kramer test or unpaired $t$-test was used when appropriate. Statistical analyses were performed with SPSS version 25 (IBM, Armonk, NY) and StatLight \#4 (Yukms, Kawasaki, Japan) software. A value of $p<0.05$ was considered statistically significant.

\section{RESULTS}

\section{Body weight and water intake during the experimental period}

Body weight gain in CONT $(n=7)$, HEAT $(n=7)$, cdsCONT $(n=6)$ and cds-HEAT $(n=7)$ during the 
experimental period is shown in Fig. 2A. As determined by a two-way repeated measures ANOVA, effects of heat exposure $\left(F_{(1,23)}=4.072, p=0.055\right)$, candesartan treatment $\left(F_{(1,23)}=0.980, p=0.332\right)$ or the interaction of exposure $\times$ treatment $\left(F_{(1,23)}=4.072, p=0.055\right)$ were not found, although body weight gain in the HEAT group was transiently attenuated in the early phase of the experiment (day 3). Along with no effect of heat exposure or candesartan treatment, there was no significant interaction of exposure $\times$ drug interaction in the daily water intake $\left(F_{(1,}, 23\right)=0.627$, $p=0.437$ ) (Fig. 2B).

\section{Effects of short-term heat exposure on water intake, plasma osmolality and circulating hormones}

Rats of the HEAT and cds-HEAT groups exhibited drooling and flushing of the exposed skin in the auricles, palms, feet and tail. However, no abnormal behaviors were observed during or after the heat exposure.

For the 20-min water intake after normothermic or hyperthermic exposure, a two-way ANOVA showed a significant interaction of exposure $\times$ treatment on day 1 $\left(F_{(1,23)}=9.046, p=0.006\right)$, day $4\left(F_{(1,23)}=6.840\right.$, $p=0.015)$ and day $7\left(F_{(1,23)}=7.006, p=0.014\right)$, and further multiple comparisons indicated an increased water intake in the HEAT group $(p<0.05$, TukeyKramer's test) (Fig. 3). The effect of heat exposure was significant on all of the experimental days $\left(F_{(1,23)}=\right.$ 7.631, $p=0.011$, CONT vs. HEAT, $p=0.037$, unpaired $t$-test, minimal statistics, day 3 ). An effect of candesartan treatment was found on all experimental days except for day 3 and day $6\left(F_{(1,23)}=4.959, p=\right.$ 0.036, HEAT vs. cds-HEAT, $p=0.045$, minimal statistics, day 2). From these results, we concluded that short-term heat exposure and candesartan treatment were mostly physiologically effective.

Plasma osmolality and hormone concentration were measured in plasma samples, which were successfully collected from animals in both the circadian resting phase and post-exposure period (CONT, $n=5$; HEAT, $n=4$, cds-CONT, $n=5$; cds-HEAT, $n=5$ ) (Table 1).

Plasma osmolality during the circadian resting phase was not different between the groups ( $p>0.05$, TukeyKramer's test) (Table 1). In addition, as determined by a two-way ANOVA, there were no effects of heat-

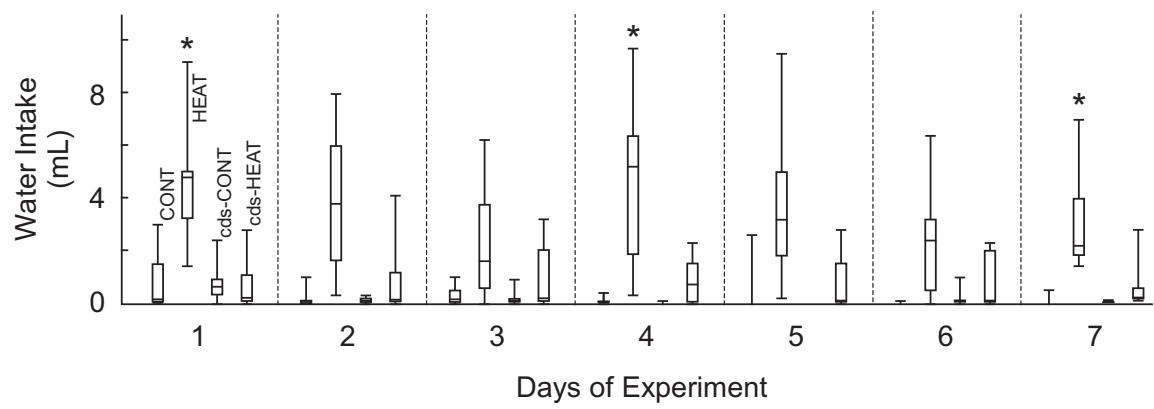

Fig. 3. Twenty-minute water intake of rats immediately after daily normothermic (CONT) or heat (HEAT) exposure, with or without candesartan (cds; $1.6-1.8 \mathrm{mg} / \mathrm{kg} /$ day). Data are displayed in box plots and were analyzed using a two-way ANOVA and the Tukey-Kramer multiple test $\left({ }^{*} p<0.05\right)$. exposure $\left.\left(F_{(1,} 34\right)=0.199, \quad p=0.659\right)$, candesartan treatment $\left(F_{(1,34)}=0.462, p=0.283\right)$ or exposure $\times$ treatment interaction $\left(F_{(1,34)}=0.004, p=0.947\right)$.

Plasma Ang II levels in the resting phase of the candesartan-treated groups showed an approximately 3fold increase compared with those of the untreated groups $(p<0.001$, Tukey-Kramer's test) (Fig. 4A, Table 1), presumably because of removal of negative feedback control of Ang II production via AT1R. A twoway ANOVA revealed a significant effect of candesartan treatment $\left(F_{(1,34)}=76.845, p<0.001\right)$, a lack of effect of heat exposure $\left(F_{(1,34)}=1.371, p=0.250\right)$ and no exposure $\times$ treatment interaction $\left(F_{(1,34)}=1.161, p=\right.$ 0.289). Further post hoc analysis showed that heat exposure induced an approximately 1.6-fold increase of Ang II levels within the candesartan-treated groups (cds-CONT vs. cds-HEAT, $p=0.039$, unpaired $t$-test), although the resting levels did not show a significant difference $(p=0.482)$ (Fig. 4A, Table 1).

Plasma corticosterone levels in the resting phase were not significantly different between the groups $(p>$ 0.05, Tukey-Kramer's test) (Fig. 4B, Table 1). However, as determined by a two-way ANOVA, there was a significant effect of heat exposure $\left(F_{(1,34)}=17.754\right.$, $p<0.001)$ but no effect of candesartan treatment $\left(F_{(1,34)}=0.146, p=0.705\right)$ nor exposure $\times$ treatment interaction $\left(F_{(1,34)}=0.001, p=0.983\right)$. Heat exposure evoked a 2.2- to 4.6-fold increase in corticosterone levels compared with the appropriate control groups (CONT vs. HEAT, $p=0.011$; cds-CONT vs. cds-HEAT, $p=0.032$, unpaired $t$-test) (Fig. 4B, Table 1). These results indicate that short-term heat exposure upregulates corticosterone levels in the systemic circulation beyond the circadian rhythm without involvement of AT1R and that this is a transient, rather than chronic, effect.

\section{Effects of short-term heat exposure on neurogenesis and protein levels in the hippocampus}

Cell bodies immunoreactive for $\mathrm{Ki}-67$ and DCX were found in the subgranular zone of the hippocampal dentate gyrus in all groups (Figs. 5 and 6). To determine the effect of short-term heat exposure on hippocampal neurogenesis, quantitative analyses of immunohistochemistry were performed using a total 20 sections ranging from the rostral tip to the caudal end of the dentate gyrus in each animal (Table 2).

For the number of $\mathrm{Ki}-67-$ immunoreactive cells, a two-way ANOVA showed no effect of heat exposure $\quad\left(F_{(1,}\right.$ 23) $=0.736, \quad p=$ 0.400), candesartan treatment $\left(F_{(1,23)}=1.875, p=0.184\right)$ or expo sure $\times$ drug interaction $\left(F_{(1,23)}=\right.$ $0.210, p=0.651$ ) (Fig. 7, Table 2). However, for the number of DCXimmunoreactive cells, heat exposure $\left.\left(F_{(1,} 23\right)=8.754, \quad p=0.007\right)$ and candesartan treatment $\left(F_{(1,23)}=\right.$ 8.754, $p=0.007)$ were effective, 
Table 1. Mean plasma osmolality, Ang II and corticosterone concentration

\begin{tabular}{|c|c|c|c|c|c|c|c|c|}
\hline & \multicolumn{2}{|l|}{ CONT $(n=5)$} & \multicolumn{2}{|l|}{ HEAT $(n=4)$} & \multicolumn{2}{|c|}{ cds-CONT $(n=5)$} & \multicolumn{2}{|c|}{ cds-HEAT $(n=5)$} \\
\hline & Rest & $\begin{array}{l}\text { Post- } \\
\text { exposure }\end{array}$ & Rest & $\begin{array}{l}\text { Post- } \\
\text { exposure }\end{array}$ & Rest & $\begin{array}{l}\text { Post- } \\
\text { exposure }\end{array}$ & Rest & $\begin{array}{l}\text { Post- } \\
\text { exposure }\end{array}$ \\
\hline $\begin{array}{l}\text { Osmolality } \\
\qquad(\mathrm{mOsmol} / \mathrm{kg})\end{array}$ & $292.8 \pm 5.8$ & $294.0 \pm 6.8$ & $295.3 \pm 7.4$ & $292.3 \pm 3.4$ & $297.4 \pm 3.7$ & $291.4 \pm 3.6$ & $293.0 \pm 3.5$ & $297.2 \pm 6.6$ \\
\hline Ang II (ng/mL) & $1.13 \pm 0.25$ & $1.05 \pm 0.15$ & $0.96 \pm 0.08$ & $1.11 \pm 0.38$ & $3.02 \pm 0.62$ & $2.63 \pm 0.83$ & $2.74 \pm 0.58$ & $4.20 \pm 1.16$ \\
\hline $\begin{array}{l}\text { Corticosterone } \\
\qquad(\mathrm{ng} / \mathrm{mL})\end{array}$ & $64.50 \pm 23.86$ & $84.58 \pm 30.35$ & $73.12 \pm 11.65$ & $389.17 \pm 106.07$ & $99.59 \pm 32.98$ & $142.16 \pm 43.76$ & $65.93 \pm 20.86$ & $323.54 \pm 130.02$ \\
\hline
\end{tabular}

Rest: resting level estimated from blood samples collected at 10:00 on day 5 . Post-exposure: level immediately after the normothermic $\left(\mathrm{CONT}, 25.0 \pm 0.8^{\circ} \mathrm{C}\right)$ or hyperthermic (HEAT, $36.0 \pm 0.1^{\circ} \mathrm{C}$ ) exposure estimated from blood taken within 3 min after finishing the exposure around 11:00 on day 3 . Values are mean \pm SD.

A

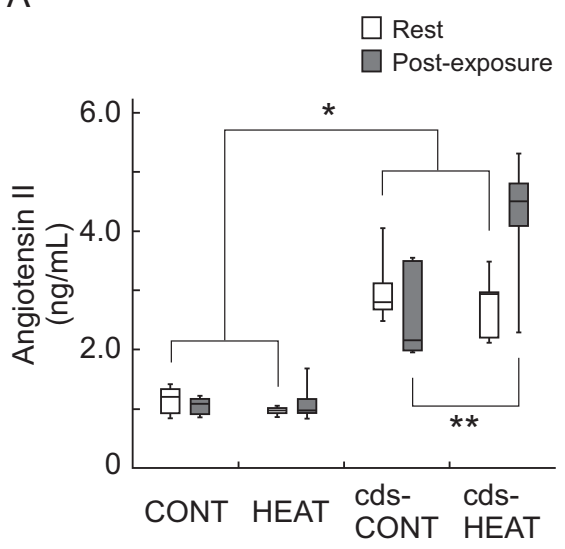

B

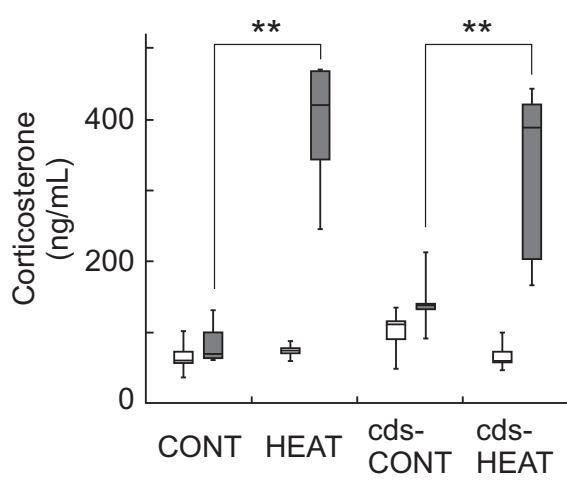

Fig. 4. Plasma hormone levels in rats exposed daily to short-term heat treatment. Rats were exposed to normothermic (CONT) or hyperthermic (HEAT) conditions for one hour per day during a 7-day experimental period, in the absence or presence of candesartan (cds; $1.6-1.8 \mathrm{mg} / \mathrm{kg} / \mathrm{day}$ ) treatment. (A) Plasma angiotensin II and (B) corticosterone levels ( $\mathrm{ng} / \mathrm{mL}$ ) in the circadian resting phase (white) and in the post-exposure (gray). Measurements were performed on blood samples collected before the exposure, at around 10:00 on day 5, for the circadian resting phase and performed on samples collected within $3 \mathrm{~min}$ of the exposure, at around 11:00 on day 3, for postexposure. Data are displayed in box plots (CONT, $n=5$; HEAT, $n=4$; cds-CONT, $n=5$; cdsHEAT, $n=5$ ) and were analyzed using a two-way ANOVA and the Tukey-Kramer multiple test $\left({ }^{*} p<0.05\right)$ or unpaired $t$-test $\left({ }^{* *} p<0.05\right)$.

with an exposure $\times$ drug interaction $\left(F_{(1,23)}=4.296, p\right.$ $=0.049)$. Further multiple comparisons showed that the number of DCX-immunoreactive cells was increased approximately 1.4 -fold in the HEAT compared with CONT group $(p=0.008$, Tukey-Kramer's test $)$; this effect was abolished by the coadministration of candesartan (cds-HEAT vs. HEAT, $p=0.008$ ), but the treatment did not affect the basal number of DCXimmunoreactive cells (cds-CONT vs. CONT, $p=0.928$ ) (Fig. 7, Table 2). These results indicate that short-term heat exposure did not induce an increased number of Ki-67-positive precursor cells in the hippocampus at the time point of sacrifice but increased the number of cells at the DCX stage, and that the positive effect was blocked to basal levels by treatment with candesartan.

AGT $(60 \mathrm{kDa})$, AT1R (45 kDa), VEGF (38 kDa) and BDNF $(27 \mathrm{kDa})$ were detected in the hippocampus in all groups by western blot analysis (Fig. 8A). In the densitometric analysis of the immunoreactive bands of VEGF, a two-way ANOVA showed a significant effect of candesartan treatment $\left(F_{(1,22)}=7.938, p=0.010\right)$ and

exposure $\times$ drug interaction $\left(F_{(1,22)}\right.$ $=9.667, p=0.005)$, with a lack of heat exposure effect $\left(F_{(1,22)}=0.453\right.$, $p=0.508$ ). Multiple comparisons showed that the relative protein level of VEGF in the HEAT group ( $n=$ $7,0.46 \pm 0.07$ ) was higher compared with that of CONT $(n=7,0.23 \pm 0.07$ $; p=0.047$, Tukey-Kramer's test); this upregulation was not observed when candesartan was given (cds-HEAT, $n=7, \quad 0.11 \pm 0.03, \quad p=0.001$ vs. HEAT) (Fig. 8A). Candesartan did not affect the basal level of VEGF expression (cds-CONT, $n=5$, $0.25 \pm 0.05, p=0.997$ vs. CONT). To determine the cell types expressing VEGF in the hippocampus, VEGF was immunohistochemically costained with GFAP, using the opposite hemisphere to that used for western blot analysis (Fig. 8B). Cells immunostained for VEGF were small and localized mainly in the hilus and molecular layer of the dentate gyrus, with narrow perikarya and radially arranged processes. A large number of these cells were also immunoreactive for GFAP, an astrocyte marker. These results suggest that short-term heat exposure induces VEGF synthesis through activation of AT1R in hippocampal astrocytes.

Along with a lack of effects of heat exposure and candesartan treatment, a two-way ANOVA showed no exposure $\times$ drug interaction in the relative protein levels of BDNF (CONT, $0.17 \pm 0.13$; HEAT, $0.23 \pm 0.17$; cds-CONT, $\quad 0.16 \pm 0.08 ; \quad$ cds-HEAT, $\quad 0.15 \pm 0.05$; $F_{(1,21)}=0.781, p=0.387$ ), AGT (CONT, $0.36 \pm 0.21$; HEAT, $\quad 0.19 \pm 0.07$; cds-CONT, $0.27 \pm 0.16$; cdsHEAT, $\left.0.26 \pm 0.14 ; \quad F_{(1,23)}=0.880, p=0.358\right)$ and AT1R (CONT, $0.09 \pm 0.07$; HEAT, $0.12 \pm 0.07$; cdsCONT, $0.08 \pm 0.05$; cds-HEAT, $0.07 \pm 0.06 ; F_{(1,20)}=$ $0.316, p=0.590)$.

\section{DISCUSSION}

In the present study we examined the effects of shortterm heat exposure on hippocampal neurogenesis and 

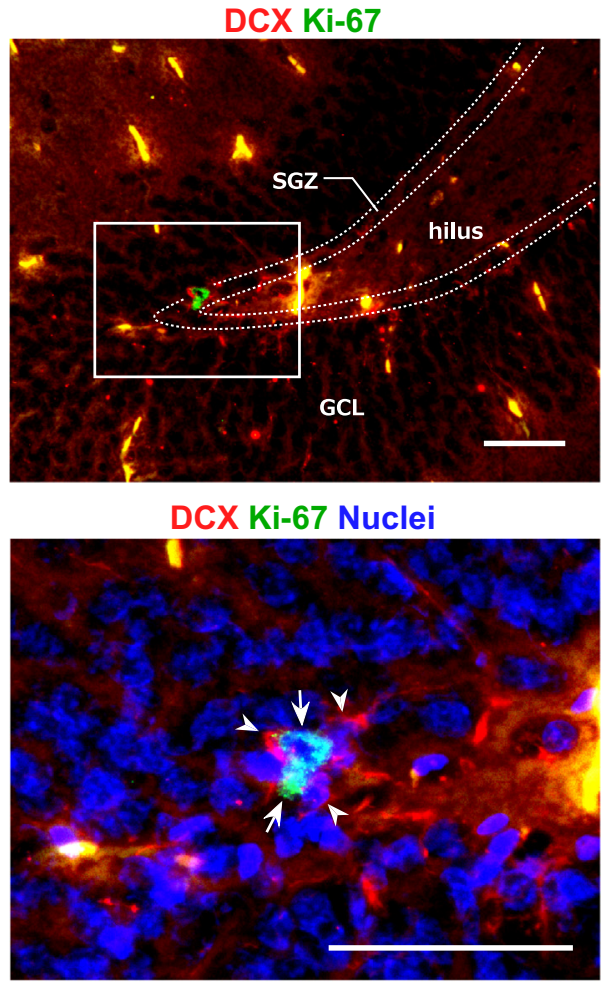

Fig. 5. Example photomicrographs showing immunoreactivity of cells for Ki-67 and doublecortin (DCX) in the hippocampal dentate gyrus of rats exposed daily to short-term heat treatment. Ki-67-immunoreactive cells (green) are indicated by arrows and DCX-immunoreactive cells (red) are indicted by arrowheads. Nuclei are counterstained with DAPI (blue). The location of the higher magnification view of the dentate gyrus (lower) is marked by a white frame in the upper photomicrograph. Broken lines indicate boundaries between the subgranular zone (SGZ), granule cell layer (GCL) and hilus. The intense yellow fluorescence is non-specific signal, most likely from blood cells. Scale bars $=100 \mu \mathrm{m}$. (For interpretation of the references to color in this figure legend, the reader is referred to the web version of this article.)

VEGF expression in adult rats. When rats were briefly exposed to a heated environment $\left(36.0 \pm 0.1{ }^{\circ} \mathrm{C}, 45 \%\right.$ humidity for $1 \mathrm{~h}$ ) once a day for 7 consecutive days, the number of DCX-expressing newborn neurons in the hippocampus showed an approximately 1.4-fold increase. The beneficial effect was abolished by AT1R blockade using candesartan. In contrast, the number of $\mathrm{Ki}$-67-expressing stem cells did not increase in the rats that underwent short-term heat exposure. DCX is exclusively expressed in immature neurons in the hippocampus within 2 weeks after birth (CouillardDespres et al., 2005). Because the number of the immature newborn neurons increased during the 7-day experimental period, these results indicate that short-term heat exposure enhances hippocampal neurogenesis by mediating AT1R activation. Meanwhile, contrary to expectations, an increased number of stem cells at the sacrifice time point were not found in the rats that underwent heat exposure. This suggests that the heat exposureenhanced neurogenesis is not necessarily due to a sustained increase in stem cells, although the mechanisms underlying the beneficial effect of the short-term heat exposure have not yet been examined.
Recently, a study on chronic heat exposure $\left(34^{\circ} \mathrm{C}\right.$ for 28 days) demonstrated enhanced hippocampal neurogenesis in mice given traumatic injury to the cerebral cortex (Umschweif et al., 2014). In addition, chronic heat exposure for hyperthermic acclimation ( $32^{\circ} \mathrm{C}$ for $40-50$ days) had no effect on hippocampal neurogenesis in rats (Matsuzaki et al., 2015). However, the effects of short-term heat stimulation on hippocampal neurogenesis have not yet been examined. To the best of our knowledge, this is the first report to show that short-term heat exposure benefits hippocampal neurogenesis. Further, because candesartan antagonizes AT1R and removes the negative feedback of Ang II, the systemic Ang II level is increased, probably conferring an increased likelihood of stimulation of the AT2R. However, effects on hippocampal neurogenesis and protein expression levels were not observed in candesartan-treated rats. Therefore, AT2R seems less likely to be involved in these phenomena, both in the resting state and following short-term heat exposure, although we did not examine effects of AT2R on hippocampal neurogenesis using antagonists in the present study. Similarly, notwithstanding the increased opportunities for Ang II to activate AT2R, using an AT1R antagonist, losartan, the beneficial effects of exercise on both hippocampal neurogenesis (Mukuda and Sugiyama, 2007) and spatial cognition (Akhavan et al., 2008) were canceled. In addition, losartan even abolishes the enhancement of hippocampal neurogenesis induced by exogenous administration of Ang II into the systemic circulation (Mukuda et al., 2014). Along with the plausible mediation by AT1R, however, an in vitro study demonstrated that AT2R mediates enhanced proliferation of neuronal stem cells derived from the fetal hippocampus (Chao et al., 2013). AT2R is well known to be abundant during fetal development in the brain, although expression levels of AT2R remain high in specific brain regions, including the hippocampus (Guimond and Gallo-Payet, 2012). In addition, in mice with traumatic brain injury, AT2R activation using an agonist, CGP42112A, promoted hippocampal neurogenesis (Umschweif et al., 2014a). A similar neurogenic effect was found by hyperthermic acclimation induced by 4-week maintenance at $34^{\circ} \mathrm{C}$, which was suppressed by treatment with an AT2R antagonist, PD123319 (Umschweif et al., 2014b). Distinct receptor subtypes of Ang II may act in the mechanisms of hippocampal neurogenesis, dependent on developmental stage and/or pathological state.

Long-term heat exposure $\left(37.5^{\circ} \mathrm{C}, 4 \mathrm{~h}\right)$ is reported to be lethal in some cases (Barney et al., 2015). In the present study, no animals died or showed abnormal behavior during or after the short-term heat exposure. However, we found an increased level of systemic CORT above the range of circadian oscillation after short-term heat exposure. The systemic level of CORT rises in response to psychological distress and a chronic increase in this steroid strongly reduces hippocampal neurogenesis (Brummelte and Galea, 2010). Activation of AT1R in the brain is known to stimulate the hypothalamus-pituitaryadrenal axis, raising the systemic level of CORT above the range of circadian oscillation (Armando et al., 2001). However, the increased level of CORT observed in the 

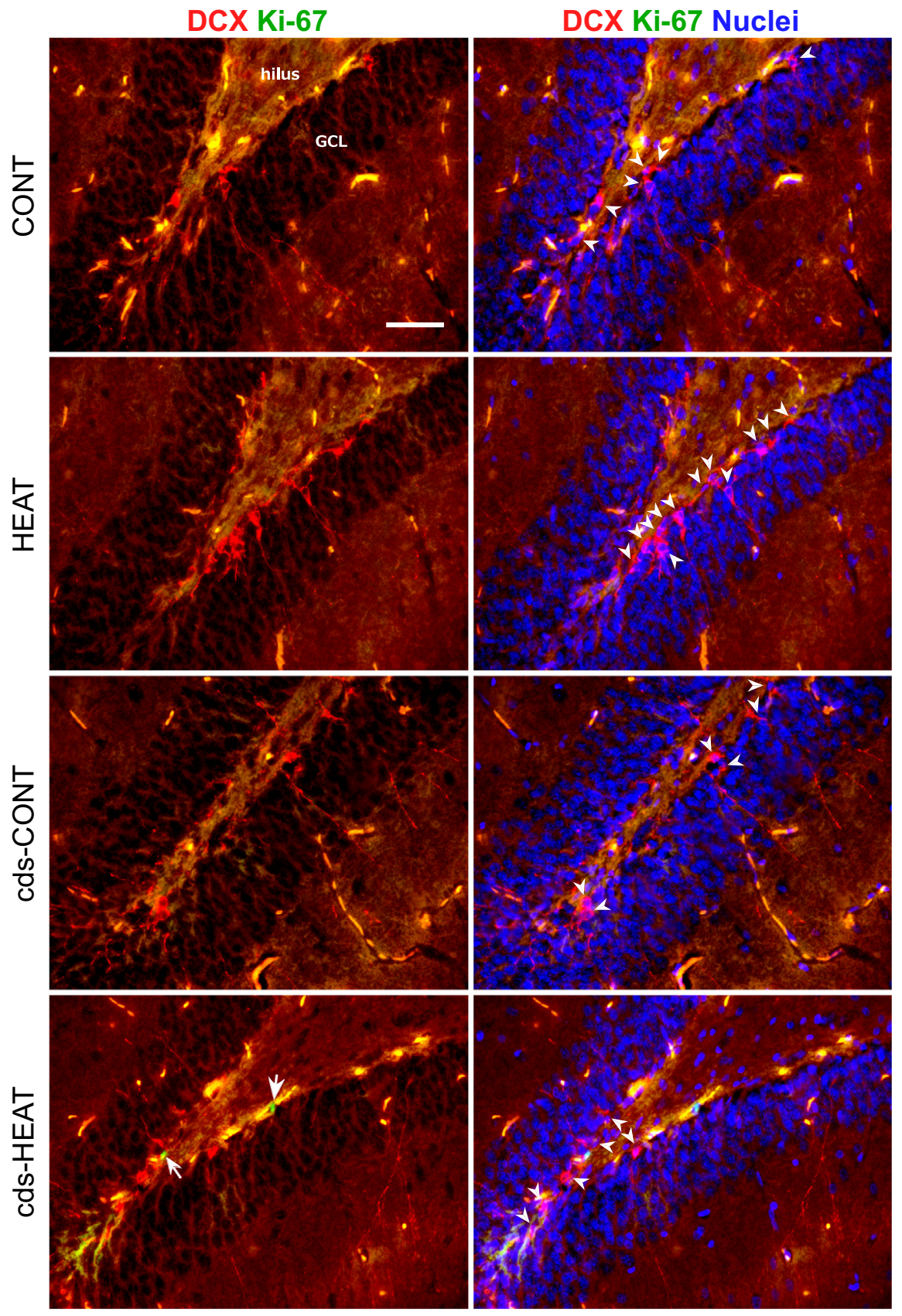

Fig. 6. Example photomicrographs showing immunoreactivity of cells for doublecortin (DCX) and $\mathrm{Ki}-67$ in the hippocampal dentate gyrus of rats exposed daily to short-term heat treatment. Rats were exposed to normothermic (CONT) or hyperthermic (HEAT) conditions for one hour per day, in the absence or presence of candesartan (cds; $1.6-1.8 \mathrm{mg} / \mathrm{kg} / \mathrm{day}$ ) treatment. DCX-immunoreactive cells (red) are indicated by arrowheads and Ki-67-immunoreactive cells (green) are indicated by arrows. Nuclei are counterstained with DAPI (blue, right column). The intense yellow fluorescence is non-specific signal, most likely from blood cells. Scale bar $=100 \mu \mathrm{m}$; all images are the same scale. GCL, granule cell layer. (For interpretation of the references to color in this figure legend, the reader is referred to the web version of this article.) present study was not sustained chronically. The post-exposure blood collection was conducted on day 3 of the study and the resting blood collection was conducted on day 5. The resting CORT level on day 5 in the heat-exposed group was restored to within the range of circadian oscillation observed in the non-heatexposed control group. In addition, a similar increase in CORT level was seen in candesartan-treated animals exposed to heat. Taken together, these results indicate that the increased level of CORT may be transient when evoked during short-term heat exposure, with regulation not dependent on AT1R. However, in an in vitro examination, AT1R activation elicited by chronic (over $24 \mathrm{~h}$ ) and high dose (over $10^{-7} \mathrm{M}$ ) application of Ang II was found to directly induce apoptosis of cultured hippocampal neural stem cells isolated from rats (Kim et al., 2017). Also, it has been shown that heart failure elicits AT1Rmediated cell death of newborn hippocampal neurons in rats (Kim et al., 2017). In the present study, however, we did not observe a decrease in neuronal progenitors or newborn neurons. Recently, we demonstrated that AT1R activation through a transient and moderate elevation of systemic Ang II level $\left(\sim 10^{-8} \mathrm{M}\right)$, induced by exogenous intravascular administration of the peptide, increases the number of newborn neurons in the rat hippocampus (Mukuda et al., 2014). Therefore, we believe that the short-term heat exposure applied in the present study causes minimal, if any, distress for the rats and that it does not elicit hyperactivation of AT1R. On the contrary, we found that expression of VEGF was enhanced mainly in hippocampal astrocytes following shortterm heat exposure, an effect that was abolished by AT1R inhibition with candesartan. VEGF is well known to exert neurogenic, angiogenic and neuroprotective effects (Udo et al.,

Table 2. Mean number of Ki-67 and doublecortin (DCX)-immunoreactive cells in the hippocampal dentate gyrus

\begin{tabular}{lllll}
\hline & CONT $(n=7)$ & HEAT $(n=7)$ & cds-CONT $(n=6)$ & cds-HEAT $(n=7)$ \\
\hline Ki-67 & $34.9 \pm 16.5$ & $46.0 \pm 16.1$ & $50.3 \pm 14.5$ & $53.7 \pm 33.9$ \\
DCX & $432.3 \pm 61.8$ & $606.1 \pm 130.5$ & $401.7 \pm 47.7$ & $432.3 \pm 92.6$ \\
\hline
\end{tabular}

Values are mean \pm SD. 


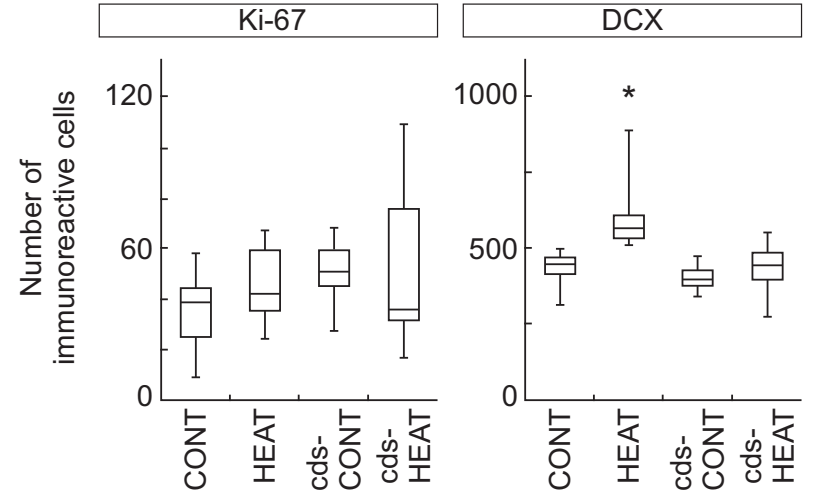

Fig. 7. Quantification of Ki-67- and DCX-immunoreactive cells in the hippocampal dentate gyrus of rats exposed daily to short-term heat treatment. Rats were exposed to normothermic (CONT) or hyperthermic (HEAT) conditions for one hour per day, in the absence or presence of candesartan (cds; $1.6-1.8 \mathrm{mg} / \mathrm{kg} /$ day) treatment. The mean number of cells immunoreactive for Ki-67 (left) or DCX (right) is shown. The mean was determined from total number of immunoreactive cells counted in all 20 sections per animal. Data are displayed in box plots (CONT, $n=7$; HEAT, $n=7$; cds-CONT, $n=6$; cdsHEAT, $n=7$ ) and were analyzed using a two-way ANOVA and the Tukey-Kramer multiple test $\left({ }^{*} p<0.05\right)$.

2008; Beazley-Long et al., 2013). In addition, astrocytes in the mouse hippocampal dentate gyrus are reported to express AT1R (Füchtbauer et al., 2011). In peripheral tissues, AT1R activation stimulates synthesis of VEGF and placental growth factor, together with cell proliferation, in various cells including endothelial cells, smooth muscle cells and podocytes (Kang et al., 2006; Pan et al., 2010). Taken together, upregulation of VEGF following short-term heat exposure may be mediated by AT1R on astrocytes, resulting in promotion of cell proliferation and/or newborn neuron survival, with subsequent enhancement of hippocampal neurogenesis. Simultaneously, short-term heat exposure may upregulate another neuroprotective factor, plasminogen activator inhibitor-1, because activation of AT1R on astrocytes stimulates synthesis and release of such factors (Rydzewski et al., 1992; Soeda et al., 2008), contributing to the survival of newborn neurons. In addition, heat shock protein 27 (HSP 27), which is inducible by heat shock, ischemia and other cellular stressors, could participate in neuroprotection in the brain. The molecule is induced in astrocytes in the ischemic region (Sharp et al., 2013) and protects against hippocampal cell death in ischemia model mice, presumably through its phosphorylation (Sharp et al., 2013). Although it has not yet been thoroughly examined in astrocytes in the brain, Ang II/AT1R signaling is reported to stimulate HSP 27 phosphorylation in smooth muscle cells of blood vessels (Meier et al., 2001).

The origin of the Ang II that activates astrocytic AT1R in the hippocampus may trace back to the periphery: there is a possibility of direct action of Ang II from the systemic circulation. In the present study, we observed an approximately 1.8-fold increase in resting Ang II levels after short-term heat exposure in candesartantreated animals, and only a marginal increase in Ang II in non-candesartan-treated animals. Similarly, heat exposure increases systemic Ang II levels in rodents
(Wang et al., 2015). As discussed below, short-term heat exposure may induce a transient and physiologically significant increase in systemic level of Ang II in rats, although a statistically significant increase in heatexposed rats was not found in this study. If systemic Ang II acts directly on hippocampal components such as astrocytes to induce VEGF production, it is necessary for the peptide to penetrate into the brain parenchyma from the systemic circulation. Almost all brain areas, including the hippocampus, are localized inside the blood-brain barrier (BBB), meaning that plasma constituents such as peptides or proteins cannot penetrate into the brain parenchyma. However, it has been proposed that the rostral part of the hippocampus is susceptible to plasma molecules because of diffusion of peptides or proteins derived from the blood stream via the subfornical organ (SFO), which is a midline structure lacking the BBB and located immediately rostral to the hippocampus (Ueno et al., 1994, 2000). In preliminary studies, we have also observed similar leakage of Evans blue, a BBBimpermeable chemical, when injected intravascularly in the rostral part of the hippocampus (S. Hamasaki, unpublished observation).

In addition to the peripheral RAS, a local RAS in the brain has been widely accepted to exist because of RAS components present in the brain, although it is difficult to detect appreciable levels of brain renin, which is the rate-limiting enzyme in the RAS (Huber et al., 2017). In fact, astrocytes in the brain synthesize AGT and constitutively secrete it into the interstitial space, thereby providing the majority of AGT in brain tissue (Stornetta et al., 1998). In addition, Ang II plays the role of a neuromodulator to affect hippocampal synaptic transmission (Wayner et al., 1993; Armstrong et al., 1996). Recently, van Thiel et al. (2017) suggested the possibility that Ang II detected in the brain is likely to be produced by circulating renin that enters the brain by crossing the BBB and acts on brain AGT, because brain renin levels correlated with plasma renin levels. In the present study, we observed the expression of AGT and AT1R in the hippocampus, but western blot analysis did not show significant changes of the levels of these proteins following short-term heat exposure. Therefore, if any Ang II is produced in the hippocampus it may not strongly contribute to the mechanisms underlying the enhanced neurogenesis. However, the relative contributions of blood-derived or brain Ang II are difficult to examine; they are hard to isolate from each other because Ang II circulating in blood possibly diffuses from the SFO into the hippocampus, as discussed above. Further studies examining the origin of Ang II are needed to elucidate the regulatory mechanisms underlying the enhanced neurogenesis following shortterm heat exposure.

In the present study, we unexpectedly observed that short-term heat exposure induces a marginal further increase of systemic Ang II that does not reach the level of statistical significance, although water intake was robustly promoted. Conversely, a significant increase in Ang II level was found in candesartan-treated animals exposed to heat. Systemic Ang II is rapidly produced in response to body fluid loss and is rapidly removed (with 
A
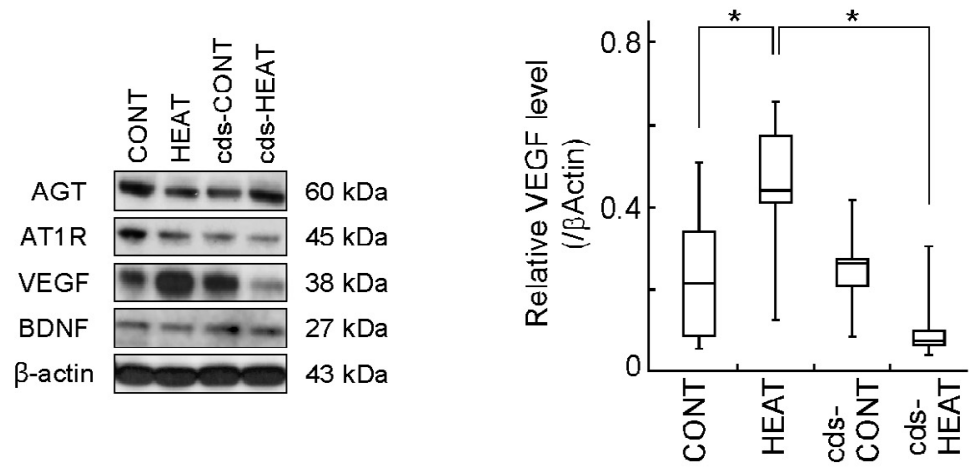

B
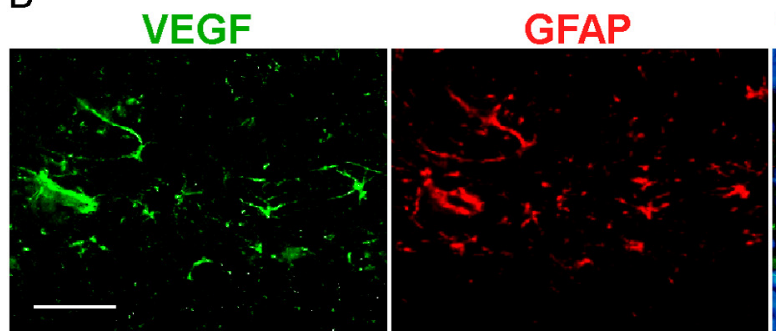

VEGF GFAP Nuclei

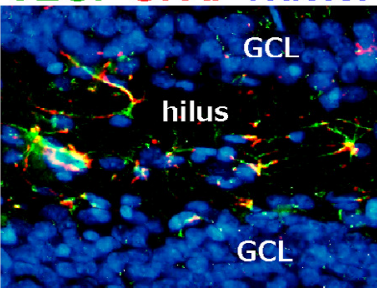

Fig. 8. Expression of various proteins in the hippocampi of rats exposed daily to short-term heat treatment. Rats were exposed to normothermic (CONT) or hyperthermic (HEAT) conditions for one hour per day, in the absence or presence of candesartan (cds; $1.6-1.8 \mathrm{mg} / \mathrm{kg} / \mathrm{day}$ ) treatment (A) Western blot signals of angiotensinogen (AGT), angiotensin II type 1 receptor (AT1R), brainderived neurotrophic factor (BDNF) and vascular endothelial growth factor (VEGF), together with $\beta$-actin used as the loading control (CONT, $n=7$; HEAT, $n=7$; cds-CONT, $n=5$; cds-HEAT, $n=7)$. Densitometric analysis of VEGF expression obtained from western blot signals is displayed in box plots. Data were analyzed using a two-way ANOVA and the Tukey-Kramer multiple test $\left({ }^{*} p<0.05\right)$. (B) Example photomicrograph showing immunoreactivity for VEGF (green) and glial fibrillary acidic protein (GFAP, red) in the hippocampal dentate gyrus of a heattreated rat. Nuclei are counterstained with DAPI (blue). The yellow fluorescence in the merged image indicates double-positive VEGF and GFAP expression. Scale bar $=50 \mu \mathrm{m}$. GCL, granule cell layer. (For interpretation of the references to color in this figure legend, the reader is referred to the web version of this article.)

a $15 \mathrm{~s}$ half-life) from the systemic circulation by an aminopeptidase from the endothelium, after eliciting various physiological functions such as promotion of aldosterone synthesis and secretion, and perception of thirst (Fitzsimons, 1998). In addition, systemic levels of Ang II are regulated by negative feedback, in which systemic Ang II activates AT1R in the kidney to allow a rapid and tonic suppression of release of renin, the rate-limiting step in the formation of Ang II in the systemic circulation (Fitzsimons, 1998). Thus, blockade of AT1R by specific antagonists such as candesartan pharmacologically abolishes the negative feedback of Ang II, leading to a several-fold increase in plasma renin and a consequent increase in Ang II plasma concentration (Shricker et al., 1997; Atlas, 2007). In the present study, candesartantreated rats exposed to heat displayed drooling (probably leading to body fluid loss) and showed increased levels of systemic Ang II, but water intake was significantly attenuated immediately after the short-term heat exposure.
Therefore, candesartan acts on central and peripheral AT1R, subsequently diminishing thirst perception and suppressing the negative feedback in candesartan-treated rats exposed to heat. Taken together, it is plausible that short-term heat exposure transiently increased systemic Ang II levels to stimulate water intake, but the increased levels were quickly restored to near-basal levels by physiologically activated negative feedback by the time of blood collection.

The present study revealed that short-term heat exposure is beneficial for hippocampal neurogenesis in adult rats, which may be mediated by increased VEGF expression in hippocampal astrocytes. These benefits would be mediated by activation of AT1R, probably expressed in the hippocampus, because they are abolished under blockade by AT1R. This idea is not contradictory to our previous findings that activation of AT1R elicited by exogenous Ang II enhances hippocampal neurogenesis and that the systemic Ang II level is acutely and transiently increased during running exercise, probably as a result of body fluid loss (Mukuda et al., 2014). In addition, blockade of AT1R attenuates exercise-enhanced hippocampal neurogenesis in rats and restores it to basal levels (Mukuda and Sugiyama, 2007). Physical exercise is a strong stimulus for enhancing hippocampal neurogenesis through direct or indirect actions of neurotrophic factors, improving hippocampal functions such as learning and memory (van Praag et al., 1999; Cao et al., 2004; Udo et al., 2008; Speisman et al., 2013). In addition, AT1R in the brain has been suggested to be important for improving hippocampal function in rats, because blockade of central AT1R prevents the beneficial effects of physical exercise on spatial learning and memory (Akhavan et al., 2008). Taken together, Ang IIAT1R signals are likely to be essential for the regulation of exercise-enhanced neurogenesis that maintains and improves hippocampal function. As an alternative to physical exercise, short-term heat exposure may be an easy and efficacious stimulus to enhance hippocampal neurogenesis when it is difficult to perform physical exercise because of injury, disease or aging, because it may elicit mechanisms common to those observed in exercisedependent enhancement of hippocampal neurogenesis. Our findings in the present study provide support for further investigations to advance thermal therapy for maintaining and improving hippocampal function. 


\section{FUNDING}

This work was supported by the Japan Society for the Promotion of Science (Grant-in-Aid for Scientific Research (C) \#15K0161).

\section{COMPETING INTERESTS}

None.

\section{ACKNOWLEDGMENTS}

We wish to thank Prof. Ukena for use of a vapor osmometer and valuable suggestions, and Drs. Inaga and Okazaki for valuable comments. We thank Melony Black, PhD, and Ann Turnley, PhD, from Edanz Group (www.edanzediting.com/ac) for editing a draft of this manuscript. This work was supported by the Japan Society for the Promotion of Science, Grant Number JP15K0161.

\section{AUTHOR CONTRIBUTIONS}

Y.K. and T.M. designed research; Y.K., T.M., S.H., H.N. and T.K. performed experiments; and Y.K. and T.M. analyzed data and wrote the manuscript.

\section{REFERENCES}

Akhavan MM, Emami-Abarghoie M, Sadighi-Moghaddam B, Safari M, Yousefi Y, Rashidy-Pour A (2008) Hippocampal angiotensin II receptors play an important role in mediating the effect of voluntary exercise on learning and memory in rat. Brain Res 1232:132-138. https://doi.org/10.1016/i.brainres.2008.07.042.

Armando I, Carranza A, Nishimura Y, Hoe KL, Barontini M, Terrón JA, Falcón-Neri A, Ito T, et al. (2001) Peripheral administration of an angiotensin II AT(1) receptor antagonist decreases the hypothalamic-pituitary-adrenal response to isolation Stress. Endocrinology 142:3880-3889.

Armstrong DL, Garcia EA, Ma T, Quinones B, Wayner MJ (1996) Angiotensin II blockade of long-term potentiation at the perforant path-granule cell synapse in vitro. Peptides 17:689-693.

Atlas SA (2007) The renin-angiotensin aldosterone system: pathophysiological role and pharmacologic inhibition. J Manag Care Pharm 13:9-20. https://doi.org/10.18553/jmcp.2007.13.s8b.9.

Barney CC, Schanhals EM, Grobe JL, Andresen BT, Traver M (2015) Heat acclimation and thirst in rats. Physiol Rep 3. https://doi.org/ 10.14814/phy2.12642. pii:e12642.

Beazley-Long N, Hua J, Jehle T, Hulse RP, Dersch R, Lehrling C, Bevan H, Quu $Y$, et al. (2013) VEGF-A165b is an endogenous neuroprotective splice isoform of vascular endothelial growth factor A in vivo and in vitro. Am J Pathol 183:918-929. https://doi. org/10.1016/j.ajpath.2013.05.031.

Brummelte S, Galea LA (2010) Chronic high corticosterone reduces neurogenesis in the dentate gyrus of adult male and female rats. Neurosci 168:680-690. https://doi.org/10.1016/j. neuroscience.2010.04.023.

Cao L, Jiao X, Zuzga DS, Liu Y, Fong DM, Young D, During MJ (2004) VEGF links hippocampal activity with neurogenesis, learning and memory. Nat Genet 36:827-835.

Chao J, Yang L, Buch S, Gao L (2013) Angiotensin II increased neuronal stem cell proliferation: role of AT2R. PLoS ONE 8: e63488. https://doi.org/10.1371/journal.pone.0063488.

Couillard-Despres S, Winner B, Schaubeck S, Aigner R, Vroemen M, Weidner N, Bogdahn U, Winkler J, Kuhn HG, Aigner L (2005) Doublecortin expression levels in adult brain reflect neurogenesis. Eur J Neurosci 21:1-14.
Fabel K, Fabel K, Tam B, Kaufer D, Baiker A, Simmons N, Kuo CJ, Palmer TD (2003) VEGF is necessary for exercise-induced adult hippocampal neurogenesis. Eur J Neurosci 18:2803-2812.

Fitzsimons JT (1998) Angiotensin, thirst, and sodium appetite. Physiol Rev 78:583-686.

Füchtbauer L, Groth-Rasmussen M, Holm TH, Løbner M, ToftHansen H, Khorooshi R, Owens T (2011) Angiotensin II Type 1 receptor (AT1) signaling in astrocytes regulates synaptic degeneration-induced leukocyte entry to the central nervous system. Brain Behav Immun 25:897-904. https://doi.org/ 10.1016/j.bbi.2010.09.015.

Gohlke P, Von Kügelgen S, Jürgensen T, Kox T, Rascher W, Culman J, Unger T (2002) Effects of orally applied candesartan cilexetil on central responses to angiotensin II in conscious rats. J Hypertens 20:909-918.

Guimond MO, Gallo-Payet N (2012) The angiotensin II type 2 receptor in brain functions: an update. Int $\mathrm{J}$ Hypertens 2012:351758. https://doi.org/10.1155/2012/351758.

Huber G, Schuster F, Raasch W (2017) Brain renin-angiotensin system in the pathophysiology of cardiovascular diseases. Pharmacol Res 125A:72-90. https://doi.org/10.1016/i. phrs.2017.06.016.

Kang YS, Park YG, Kim BK, Han SY, Jee YH, Han KH, Lee MH, Song $\mathrm{HK}$, et al. (2006) Angiotensin II stimulates the synthesis of vascular endothelial growth factor through the p38 mitogen activated protein kinase pathway in cultured mouse podocytes. J Mol Endocrinol 36:377-388.

Kim MS, Lee GH, Kim YM, Lee BW, Nam HY, Sim UC, Choo SJ, Yu SW, et al. (2017) Angiotensin II causes apoptosis of adult hippocampal neural stem cells and memory impairment through the action on AMPK-PGC1 $\alpha$ signaling in heart failure. Stem Cells Transl Med 6:1491-1503. https://doi.org/10.1002/sctm.16-0382.

Matsuzaki K, Katakura M, Inoue T, Hara T, Hashimoto M, Shido O (2015) Aging attenuates acquired heat tolerance and hypothalamic neurogenesis in rats. J Comp Neurol 523:1190-1201. https://doi.org/10.1002/cne.23732.

Meier M, King GL, Clermont A, Perez A, Hayashi M, Feener EP (2001) Angiotensin $A T_{1}$ receptor stimulates heat shock protein 27 phosphorylation in vitro and in vivo. Hypertension 38:1260-1265. https://doi.org/10.1161/hy1201.096573.

Mukuda T, Koyama Y, Hamasaki S, Kaidoh T, Furukawa Y (2014) Systemic angiotensin II and exercise-induced neurogenesis in adult rat hippocampus. Brain Res 1588:92-103. https://doi.org/ 10.1016/j.brainres.2014.09.019.

Mukuda T, Sugiyama H (2007) An angiotensin II receptor antagonist suppresses running-enhanced hippocampal neurogenesis in rat. Neurosci Res 58:140-144. https://doi.org/10.1016/j. neures.2007.02.005.

Pan P, Fu H, Zhang L, Huang H, Luo F, Wu W, Guo Y, Liu X (2010) Angiotensin II upregulates the expression of placental growth factor in human vascular endothelial cells and smooth muscle cells. BMC Cell Biol 26:11-36. https://doi.org/10.1186/1471-212111-36.

Paxinos G, Watson C (2009) The rat brain in stereotaxic coordinates, compact. sixth ed. Amsterdam: Elsevier.

Rydzewski B, Zelezna B, Tang W, Sumners C, Raizada MK (1992) Angiotensin II stimulation of plasminogen activator inhibitor-1 gene expression in astroglial cells from the brain. Endocrinology 130:1255-1262. https://doi.org/10.1210/endo.130.3.1537291.

Saavedra JM (2017) Beneficial effects of angiotensin II receptor blockers in brain disorders. Pharmacol Res 125A:91-103. https:/ doi.org/10.1016/j.phrs.2017.06.017.

Sharp FR, Zhan X, Liu DZ (2013) Heat shock proteins in the brain: role of Hsp70, Hsp 27, and HO-1 (Hsp32) and their therapeutic potential. Transl Stroke Res 4:685-692. https://doi.org/10.1007/ s12975-013-0271-4.

Shricker K, Holmer S, Krämer BK, Riegger GA, Kurtz A (1997) The role of angiotensin II in the feedback control of renin gene expression. Pflugers Arch 434:166-172.

Soeda S, Koyanagi S, Kuramoto Y, Kimura M, Oda M, Kozako T, Hayashida S, Shimeno H (2008) Anti-apoptotic roles of 
plasminogen activator inhibitor-1 as a neurotrophic factor in the central nervous system. Thromb Haemost 100:1014-1020.

Speisman RB, Kumar A, Rani A, Foster TC, Ormerod BK (2013) Daily exercise improves memory, stimulates hippocampal neurogenesis and modulates immune and neuroimmune cytokines in aging rats. Brain Behav Immun 28:25-43. https:// doi.org/10.1016/j.bbi.2012.09.013.

Stornetta RL, Hawelu-Johnsonm CL, Guyenet PG, Lynch KR (1998) Astrocytes synthesize angiotensinogen in brain. Science 242:1444-1446.

Udo H, Yoshida Y, Kino T, Ohnuki K, Mizunoya W, Mukuda T, Sugiyama H (2008) Enhanced adult neurogenesis and angiogenesis and altered affective behaviors in mice overexpressing vascular endothelial growth factor $120 . \mathrm{J}$ Neurosci 28:14522-14536. https://doi.org/10.1523/ JNEUROSCI.3673-08.2008.

Ueno M, Akiguchi I, Hosokawa M, Yagi H, Takemura M, Kimura J, Takeda T (1994) Accumulation of blood-borne horseradish peroxidase in medial portions of the mouse hippocampus. Acta Neurol Scand 90:400-404.

Ueno M, Akiguchi I, Hosokawa M, Kotani H, Kanenishi K, Sakamoto $H$ (2000) Blood-brain barrier permeability in the periventricular areas of the normal mouse brain. Acta Neuropathol 99:385-392.

Umschweif G, Liraz-Zaltsman S, Shabashov D, Alexandrovich A, Trembovler V, Horowitz M, Shohami E (2014) Angiotensin receptor type 2 activation induces neuroprotection and neurogenesis after traumatic brain injury. Neurotherapeutics 11:665-678. https://doi.org/10.1007/s13311-014-0286-x.

Umschweif G, Shabashov D, Alexandrovich AG, Trembovler V, Horowitz M, Shohami E (2014) Neuroprotection after traumatic brain injury in heat-acclimated mice involves induced neurogenesis and activation of angiotensin receptor type 2 signaling. J Cereb Blood Flow Metab 34:1381-1390. https://doi. org/10.1038/jcbfm.2014.93.

van Praag H, Christie BR, Sejnowski TJ, Gage FH (1999) Running enhances neurogenesis, learning, and long-term potentiation in mice. Proc Natl Acad Sci USA 96:13427-13431.

van Thiel BS, Góes Martini A, Te Riet L, Severs D, Uijl E, Garrelds IM, Leijten FPJ, van der Pluijm I, et al. (2017) Brain reninangiotensin system: does it exist? Hypertension 69:1136-1144. https://doi.org/10.1161/HYPERTENSIONAHA.116.08922.

Vaynman S, Ying Z, Gomez-Pinilla F (2004) Hippocampal BDNF mediates the efficacy of exercise on synaptic plasticity and cognition. Eur J Neurosci 20:2580-2590.

Wang X, Yuan B, Dong W, Yang B, Yang Y, Lin X, Gong G (2015) Humid heat exposure induced oxidative stress and apoptosis in cardiomyocytes through the angiotensin II signaling pathway. Heart Vessels 30:396-405. https://doi.org/10.1007/s00380-0140523-6.

Wayner MJ, Armstrong DL, Polan-Curtain JL, Denny JB (1993) Role of angiotensin II and AT1 receptors in hippocampal LTP. Pharmacol Biochem Behav 45:455-464. 